\title{
Spatio-temporal evolution of onychomadesis in a child with missed Kawasaki disease
}

\author{
Aaqib Zaffar Banday ${ }^{1} \cdot$ Harsha Neelam ${ }^{1} \cdot$ Ankur Kumar Jindal $^{1}$
}

Received: 18 March 2020 / Revised: 6 April 2020 / Accepted: 8 April 2020 / Published online: 24 April 2020

(C) International League of Associations for Rheumatology (ILAR) 2020

A 4.5-year-old boy presented with shedding of the left index fingernail. He had fever 6 weeks back with rash, oral mucosal erythema, red cracked lips, and periungual skin peeling. At presentation (6 weeks into the illness), his fingernails showed different stages of onychomadesis; right index, left middle, and left little fingernails had just begun to separate, displaying a transverse white discoloration resembling leukonychia (red arrows in Fig. 1a); frank onychomadesis of right thumbnail (black arrow in Fig. 1a); and left index fingernail already shed off with a residual transverse groove (blue arrow in Fig. 1a). Investigations (at presentation to us, i.e., 6 weeks into the illness) showed thrombocytosis $\left(450 \times 10^{9} / \mathrm{L}\right)$ and elevated C-reactive protein $(18 \mathrm{mg} / \mathrm{L})$. Kawasaki disease was diagnosed, and he was treated with intravenous immunoglobulin $(2 \mathrm{~g} / \mathrm{kg}$ ) and aspirin $(4 \mathrm{mg} / \mathrm{kg} /$ day $)$. At 2 weeks of follow-up (8 weeks into the illness), nails which had just started to separate developed frank onychomadesis and right thumb nail had shed off leaving behind a transverse groove similar to left index finger. His 2-dimensional echocardiography showed normal coronaries on all visits, and aspirin was stopped at 6 weeks of follow-up (12 weeks into the illness). At this time all fingernails had healed completely (without any transverse grooves).

Onychomadesis in children can be a sequel of Kawasaki disease [1,2]. It is prudent to inquire for symptoms suggestive of Kawasaki disease in children who present with onychomadesis.

Acknowledgment The authors acknowledge Professor Surjit Singh for his help in patient management.

Ankur Kumar Jindal ankurjindal11@gmail.com

1 Allergy Immunology Unit, Department of Pediatrics, Advances Pediatrics Centre, Post Graduate Institute of Medical Education and Research (PGIMER), Chandigarh, India
Authors' contributions AZB: Inception of idea, writing of initial draft of manuscript, editing and revision of manuscript at all stages of its production, review of literature, photography, management of patient

HN: Writing of initial draft of manuscript, editing and revision of manuscript at all stages of its production, management of patient

AKJ: Evaluation, management and follow-up of the patient and editing of manuscript, critical revision of the manuscript at all stages of production and final approval

\section{Compliance with ethical standards}

Disclosures None.

Ethical approval and informed consent As this manuscript pertains only to a case report and analysis of data from previously reported patients published in the literature, specific ethics approval is not mandated. An informed consent was taken from parents of the child before inclusion into the manuscript.

\section{References}

1. Leung AKC, Leong KF, Lam JM (2019) Onychomadesis in a 20month-old child with Kawasaki disease. Case Rep Pediatr 2019: 3156736

2. Ciastko AR (2002) Onychomadesis and Kawasaki disease. CMAJ 166:1069

Publisher's note Springer Nature remains neutral with regard to jurisdictional claims in published maps and institutional affiliations. 


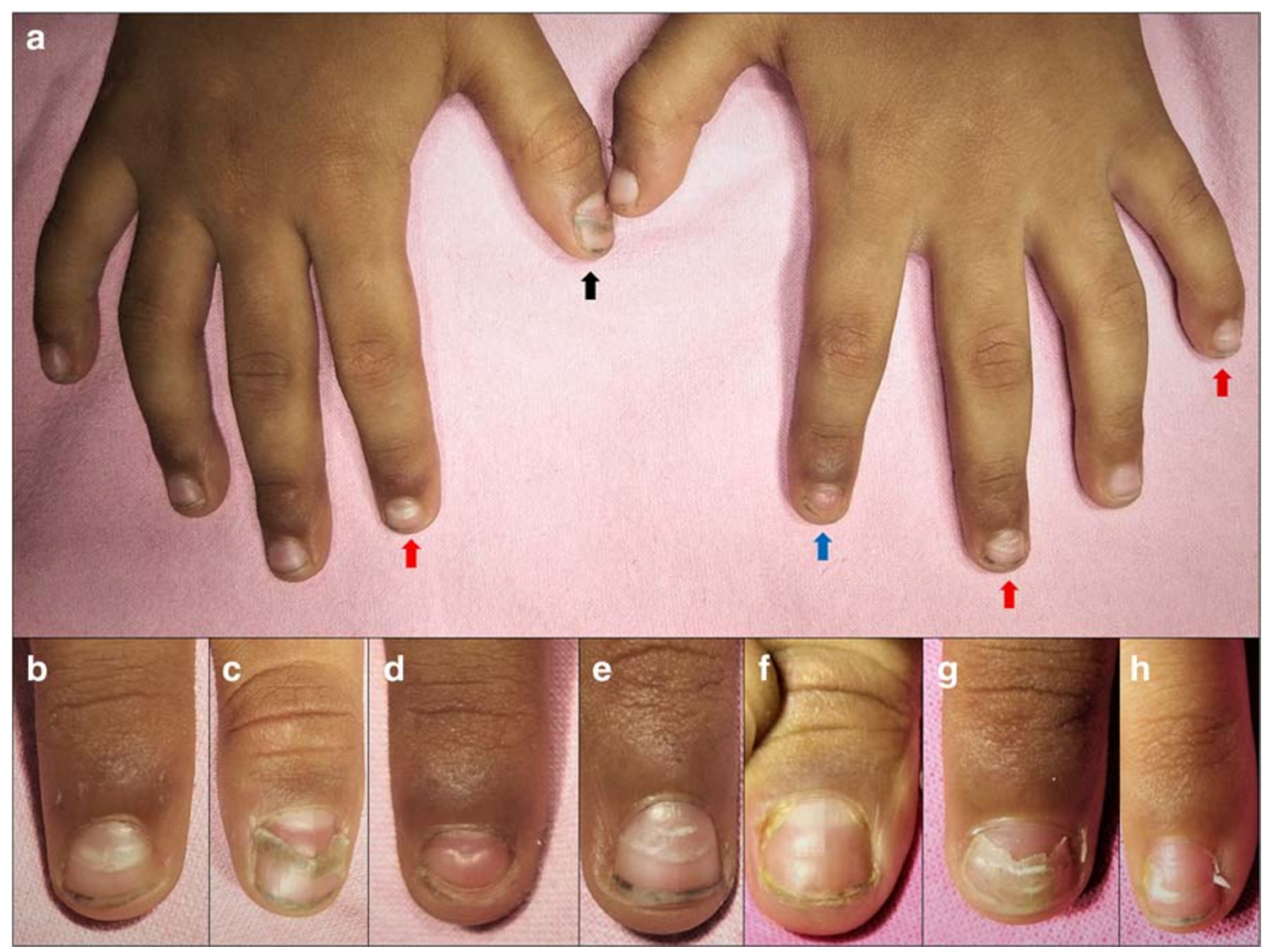

Fig. 1 Temporal evolution of onychomadesis in various fingernails. a Photograph of both hands showing onychomadesis at different stages in various finger nails. b Right index finger at presentation with a transverse white discoloration resembling leukonychia striata. $\mathbf{c}$ Right thumbnail at presentation with frank onychomadesis. d Left index fingernail at presentation with a transverse groove, resembling Beau's line, resulting from onychomadesis. e Left middle fingernail at presentation. f Right thumbnail at 2 weeks of follow-up, with temporal similarity to left index fingernail. $\mathbf{g}$ Onychomadesis of left middle fingernail. $\mathbf{h}$ Onychomadesis of left little finger 